\title{
EVALUATION METHODOLOGY OF RESIDUAL RESOURCE OF PORT CARGO HANDLING EQUIPMENT
}

\author{
Pustovyy V. M., Semenov P. O., Nesterov O. A.
}

\section{INTRODUCTION}

The need to determine the residual life of port cargo handling equipment arises when extending its service life beyond the norm for its safe operation, as well as when planning the frequency of monitoring its technical condition and repairs to ensure the reliability and efficiency of its operation ${ }^{1,2}$.

Solving the tasks of determining the residual resource is a necessary part of a set of measures to ensure the safe operation of the relevant equipment of port cargo handling facilities. The use of modern methods of assessing the degree of damage to the equipment and the theory of reliability allows us to identify additional reserves of the residual resource and to assess it with the necessary reliability.

Reliability and safety of the equipment at its development are provided by creation of a safety margin and resistance to mechanical and corrosion wear taking into account the most unfavorable operating modes. In real specific operating conditions, the intensity of resource consumption differs from the calculated one and in many cases can be determined by analyzing the load modes and the actual damage to the equipment ${ }^{3,4}$.

The choice of the method of forecasting the residual resource depends on the nature of the predominant process of degradation (wear, corrosion, fatigue, residual deformation, etc.) as well as on the required accuracy and reliability of the forecast. With low requirements for accuracy and reliability, simplified methods are used, in case of guaranteed estimates more refined methods are used, including those based on the theory of reliability ${ }^{5}$.

${ }^{1}$ Bolotin V.V. Resource of machines and constructions. M .: Mashinostroenie, 1990. 448 p.

${ }^{2}$ GOST 27.302-86. Reliability in technology. Methods for determining the permissible deviation of the technical condition and forecasting the residual life of the components of machine units.

3 GOST R 27.002-2009. Reliability in technology. Basic concepts, terms and definitions.

${ }^{4}$ RD 26.260.004-91 Forecasting the residual life of the equipment to change the parameters of its technical condition during operation Publishing house NIIHIMMASH, M. 1992. $50 \mathrm{p}$.

5 V. M. Pustovyy, M. V. Trykolenko, P. O. Semenov and others. Regulations on planned and preventive repairs of port cranes of seaports. Ministry of Transport of Ukraine, State Labor Inspectorate of Ukraine. Kyiv, 2005, part $1-250$ p., part $2-426$ p. 
It is possible to predict the residual resource at simultaneous creation of the following conditions: the known parameters defining a technical condition of the equipment (PTC - parameters of a technical condition) and criteria of a limiting condition of the equipment; there is a possibility of periodic (or continuous) control of PTC values. For some types of damage (e.g. cracking, residual deformation, mechanical and corrosion wear), not all the necessary conditions can be met, then special studies are required.

The calculation of the residual life of port cargo handling equipment is based on the concept of "safe operation of technical condition", according to which the assessment of technical condition of equipment is carried out in accordance with technical parameters that ensure its reliable and safe operation according to regulatory and (or) design documentation. As determinants we take parameters which their change (individually or in total) can lead to an inoperable or limiting condition of the equipment.

The solution to the problem of forecasting the residual life of port cargo handling equipment is to determine the term of failure due to the development of any damage or a combination of damages, provided normal operation in compliance with the rules and standards of safe use of equipment according to the parameters established in operational documents.

\section{LIFE CYCLE STUDY, INFLUENCE OF OPERATING CONDITIONS ON RESIDUAL RESOURCE}

The life cycle of any industrial equipment can be divided into three stages: design, production and operation. The stages of technical design and production and the program of work performed on them are strictly defined by standards. They predict the parameters that affect the reliability of the equipment during its operation.

The main primary period at the stage of operation of the equipment is running-in. During this period the following is carried out: systematic monitoring of the condition of the equipment; study of repair operations and operational normalization of components, units and individual parts. The analysis of documents on the account of damages and failures, reports on carrying out technical inspections, performance of warranty repairs, quantity of the spent spare parts, and also operational indicators and parameters, gives the reliable information on the general technical condition of the investigated equipment.

During the period of normal operation, in order to make full use of the equipment resource, the following systems of maintenance and restoration of good technical condition are used: "System of planned and preventive maintenance and repair"6,7 and "System of maintenance and repair of actual technical condition".

${ }^{6}$ N. F. Zubko, V. A. Yatsenko Operation and repair of port handling machines: [Textbook. for spec. Mechanization of port cargo handling works of universities], 423, [1] p. il. $22 \mathrm{~cm}$, M. Transport 1987. 
The final period of the equipment life cycle is the period of intensive growth of the flow of damages and failures. During this period of operation, the typical system of maintaining the operational condition of the equipment by eliminating emergency failures, planning maintenance and repairs is inefficient and economically unprofitable.

Thus, in the life cycle of port cargo handling equipment, the period of normal operation is of the greatest value. The maximum extension of this period is the main task in performing a set of works to study the current technical condition, residual resources and to determine the necessary measures to restore the serviceable condition of the equipment.

In the process of experimental research to determine the technical condition of individual mechanisms and all cargo handling equipment, taking into account the experience of operation and repair of such equipment in sea and river ports, it has been found that the actual application of scheduled preventive maintenance and repair is not effective enough as the technical condition of mechanisms is determined "manually" after dismantling and disassembly. At the same time mechanisms are diagnosed by individual elements (bearing, shaft, gear, etc.), i.e. the wear of individual parts of the mechanism is measured without taking into account their interaction, which reduces the quality of repair work and the perception of the general technical condition of the equipment as a whole is distorted.

Figure 1 shows the resource of a typical mechanism in the system of scheduled preventive maintenance and repair, when the scheduled repair time is set by the assigned resource $T_{r}$ and determined by the first occurrence of failures in the group of studied machines (failure probability curve).

The assigned maintenance resource calculated according to the generalized norms does not take into account the history of operating time of a particular type of equipment, especially when it works in mixed mode (light, medium and heavy), as well as general operating conditions at the enterprise (technical level of maintenance and repair personnel, quality of replacement parts, aggressive environment, etc.).

As practice shows, during scheduled repairs there is a need to dismantle and disassemble serviceable mechanisms and units, as well as to dismantle boom systems for preventive repairs, while the full service life of mechanisms and hinges is not used, and the time $\mathrm{T}_{\mathrm{f}}$ of necessary repairs according to the actual situation is significantly more.

${ }^{7}$ Non-destructive testing: Handbook: In 7 vols. ed. V. V. Klyueva. V 7: In 2 books. Book 1: V. I. Ivanov, I.E. Vlasov. Acoustic emission method / Book 2: F. Ya. Balytskiy, A. V. Barkob, N. A. Barkova and others. Vibrodiagnostics. M.: Mashinostroenie, 2005. 829 p.: il. 


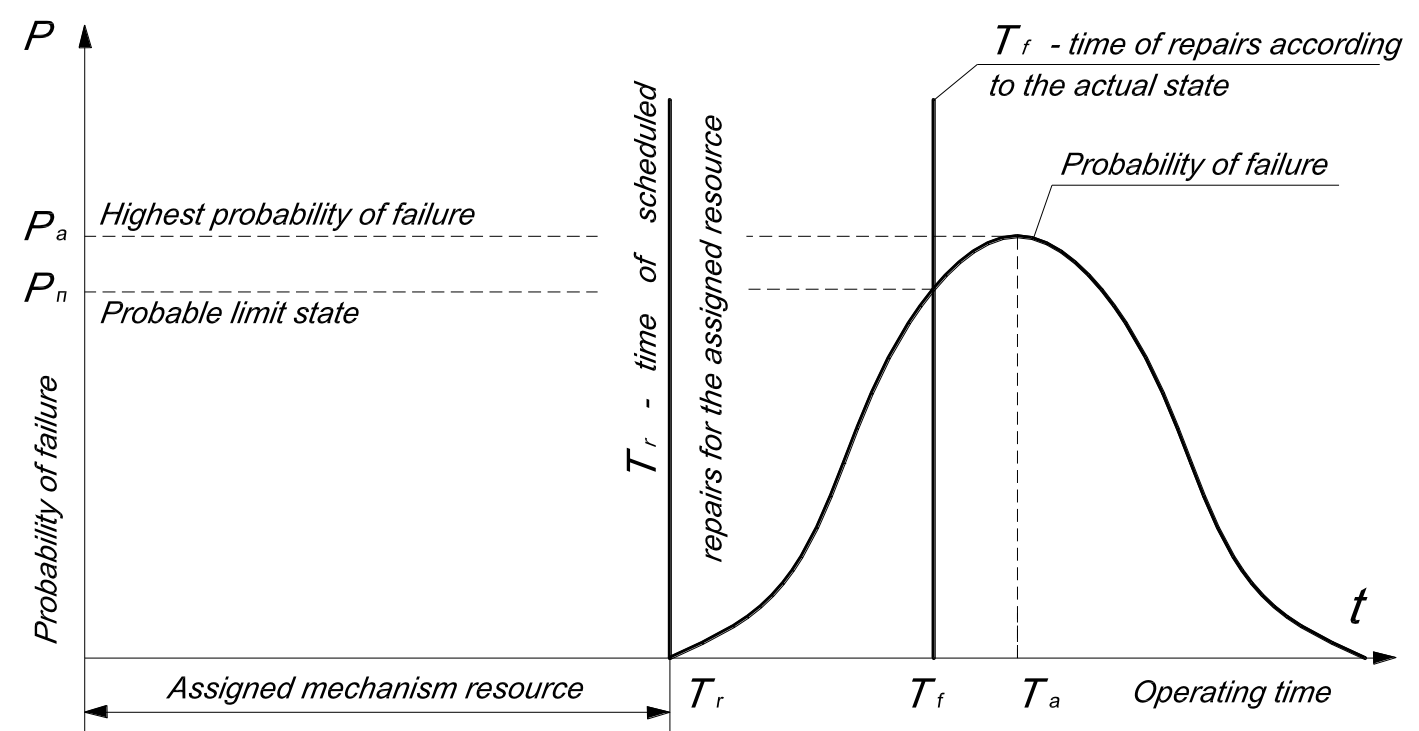

Fig. 1. Resource of a typical mechanism of cargo handling equipment in the system of scheduled and preventive maintenance and repair

Figure 2 shows the classical dependence of changes in the level of technical condition on the operating time of the mechanism ${ }^{8}$.

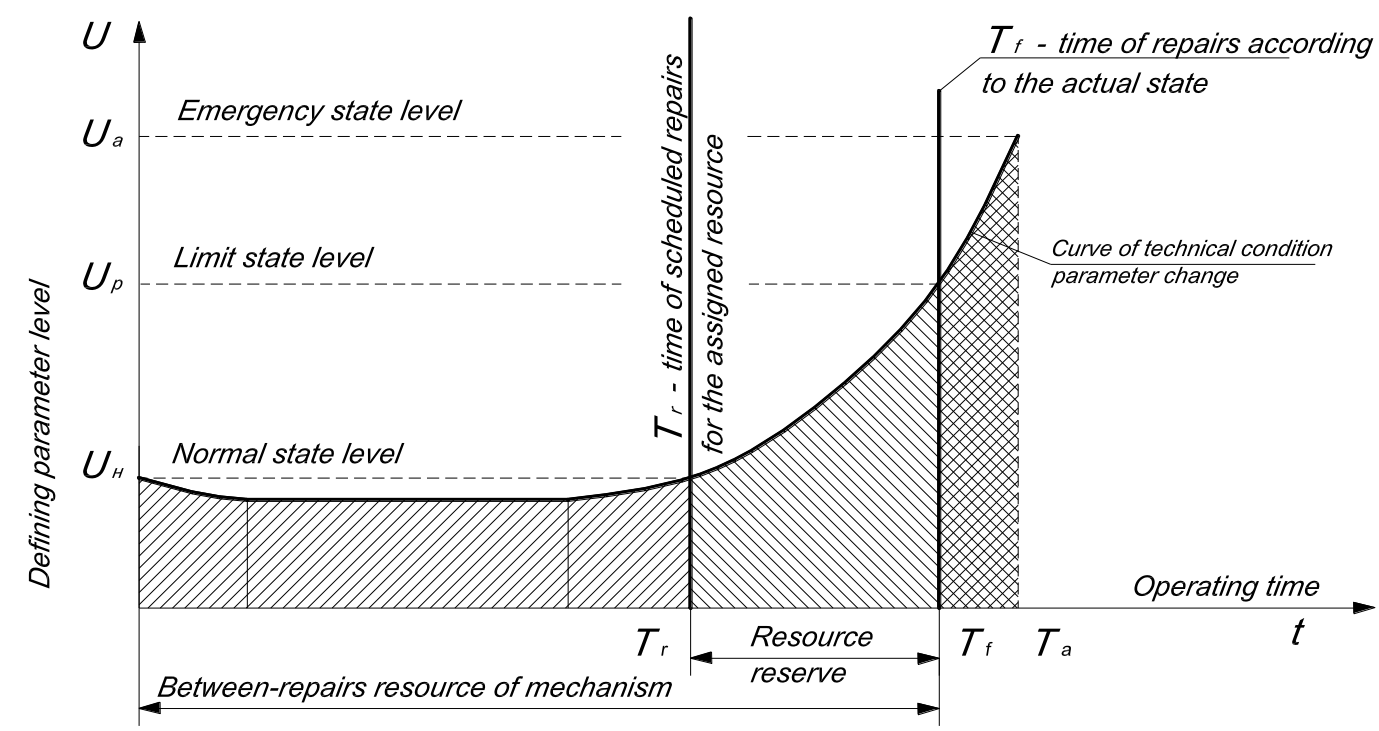

Fig. 2. The resource of the mechanism, determined by the actual technical condition.

The graph identifies three levels of technical condition: normal, limit and emergency. The level of normal condition covers the periods of running-in, stable trouble-free operation and the emergence of defects. An increase in the level of normal condition indicates the appearance of wear in the parts and components of the mechanism, i.e. the development of defects. In the system

${ }^{8}$ Pustovoy V. N. Metal structures of hoisting machines. Destruction and forecasting of residual resource. Moskva : Transport, 1992. 256 p. 
of planned and preventive maintenance and repair, the assigned resource determines the period of normal operation, although the defect can develop for a long time. During the development of defects, subject to periodic monitoring of the technical condition, it is possible to predict the degree of degradation of individual elements, components and the mechanism as a whole, as well as the period of its further safe operation. When the mechanism reaches the level of the limit state, it is advisable to carry out repair work, as the mechanism has worked out the full between-repairs resource. Further safe operation of the mechanism in the range of over-limit values of the determining parameter can lead to its failure, due to the uncontrolled development of defects of individual elements and components.

As a result of experimental research to determine the full between-repairs resource of mechanisms using modern methods of technical diagnostics, it was found that the resource reserve exceeds the prescribed one by an average of 25-30 \% and allows to determine in advance the volume of repairs and plan their term. After a full between-repairs resource and a thorough repair, it is possible to significantly reduce the cost of repairing equipment and its downtime.

Many years of experience in conducting a comprehensive determination of the technical condition (technical diagnostics using modern methods of nondestructive testing) of cargo handling equipment of sea and river ports and other industrial enterprises allow to systematize and assess the impact of conditions on the residual resource.

Among these conditions, the most influential ones are climatic conditions, environmental conditions, as well as the conditions of the cultural level of operation and quality of repair and maintenance of cargo handling equipment.

Climatic conditions include the operating conditions of cargo handling equipment at low temperatures, high humidity, as well as under the action of wind loads close to the maximum allowable values.

As is known from studies of the load-bearing capacity of metal structures of cargo handling equipment at low temperatures ${ }^{9}$ the main causes of brittle fractures together with insufficient cold resistance of materials are often zones of concentration of stresses and welds, zones of fatigue cracks, which under shock and cyclic loads become brittle at stresses much lower than the value of material yield strength.

The study of temperature dependences of mechanical characteristics of steels of metal structures of hoisting machines proves that for all types of steels with decreasing temperature there is a general pattern in the change of

${ }^{9}$ Weinson A. A. Lifting and transport machines: A textbook for universities in the specialty Lifting and transport, construction, road machinery and equipment. 4th ed., reworked. and ext. M.: Mashinostroenie, 1989. 536 p.: il 
mechanical characteristics, namely: the values of $\sigma_{0,2}$ and $\sigma_{B}$ with decreasing temperature from $+20 \ldots-70{ }^{\circ} \mathrm{C}$ increase by $15 \ldots 25 \%$. This is due to the effect of low-temperature hardening, plasticity reduction and embrittlement of steels.

The study of the plasticity of welded joints of metal structures shows a significant decrease at low temperature in the zones of thermal influence under static and especially dynamic loading; the plasticity of the welded joints is approximately 2 times lower than the plasticity of the base metal; plasticity under dynamic loading in comparison with dependences at static loading in the range of low and average temperatures $\left(-60 \ldots-20^{\circ} \mathrm{C}\right)$ decreases more than 5 times.

Operation of cargo handling equipment in conditions of high humidity is characterized by increased requirements for corrosion protection of metal structures, additional measures to ensure anti-corrosion treatment of metal structures with existing and possible accumulation of moisture. Particularly dangerous is the accumulation of water in the cavities of box elements of metal structures, which under the action of low temperatures, freezing water deforms, which leads to loss of stability and a significant reduction in loadbearing capacity under nominal loads, and can lead to destruction of metal structures when operating the equipment under the passport characteristics.

Operation of cargo handling equipment under conditions of wind loads close to the maximum allowable values affects the strength of metal structures, movement mechanisms and anti-theft devices, as well as the own and cargo stability of the equipment against overturning ${ }^{10}$. The use of cargo handling equipment without taking into account the actual wind load leads to its partial or complete destruction.

The environmental operating conditions of the handling equipment are divided into non-aggressive and aggressive. Non-aggressive conditions include the operating conditions of handling equipment indoors with small temperature fluctuations, almost constant low humidity and the absence of corrosive and abrasive particles in the air. Equipment operated in such an environment, subject to compliance with the passport mode of operation, has the highest service life and residual resource.

Aggressive conditions are the conditions of operation of cargo handling equipment in the environment of marine fog, when handling chemically active substances, such as mineral fertilizers, raw materials for them, sulfur and more. Also, aggressive conditions are the conditions of operation of cargo handling equipment in conditions of elevated temperatures (foundry equipment). The cargo handling equipment which is operated in aggressive conditions has reduction of service life and resource parameters to $50 \%$ from initial values.

\footnotetext{
${ }^{10}$ Pustovoy V. N. Metal structures of hoisting machines. Destruction and forecasting of residual resource. Moskva: Transport, 1992. 256 p.
} 
Conditions of the cultural level of operation and quality of repair and maintenance of handling equipment determine its general technical condition and the degree of accumulation of damage to metal structures, mechanisms, electrical equipment and control systems. Violation of the rules of technical operation of handling equipment, operation of equipment outside the passport regimes, use in repairs and maintenance of low-quality replacement parts, repair and maintenance work by specialists whose qualifications and experience do not meet the specifics of production and current regulatory and technical requirements documents significantly reduce the residual resource and often lead to emergencies with partial or complete destruction of equipment.

\section{EVALUATION OF PARAMETERS OF STRENGTH AND DURABILITY OF ELEMENTS OF METAL STRUCTURES}

Experience shows that almost all metal structures and mechanisms of handling equipment have primary crack-like defects or acquired during operation ones. It is also known that with the current state of the technology it is impossible to avoid with absolute reliability the cracks formed in the parts, and sometimes to record their presence.

To calculate the efficiency of structures by methods of fracture mechanics requires complete information about the nature of the load. These data can be obtained using traditional experimental and analytical methods for calculating the stress-strain state of the structural elements of cranes under the action of various operational factors, dynamic overloads, stress concentration.

To use the methods of fracture mechanics in practical calculations of metal structures, in addition to traditional mechanical characteristics of materials (strength, yield strength, etc.), we need data on new parameters that characterize the basic laws of fracture of these materials under different conditions of force and physicochemical action. Such parameters include, first of all, the characteristics of crack resistance at static $K_{\mathrm{c}}$, dynamic $K_{\mathrm{dc}}$ and cyclic $K_{\mathrm{ht}}, K_{\mathrm{fc}}, \Phi(\lambda)$ loads, as well as corrosion cracking $K_{\mathrm{scc}}{ }^{11,12}$.

Within the framework of the mechanics of brittle fracture of metal structures, the calculation can be divided into the following stages:

- determining the shape, size and location of the most dangerous cracklike defect;

- the choice of the criterion of local destruction depending on the type of material, structure and nature of the load;

- establishing the pattern of fatigue (subcritical) crack propagation in a given material;

${ }_{11}^{11}$ Andreykiv A. E. Spatial problems of crack theory. Kiev: Science. opinion, 1982. 348 p.

12 Panasyuk V. V., Savruk M. P., Datsyshin A. P. Stress distribution near cracks in plates and shells. Kiev: Naukova Dumka, 1976. 444 p. 
- determination of the stress-strain state of the structural element weakened by a defect of a given configuration;

- experimental establishment of crack resistance characteristics of a given material in case of sudden and fatigue crack propagation;

- calculation of the critical crack size (or critical load), as well as the durability of the metal structure at loads below the critical.

The proposed calculation scheme can be used to assess the degree of danger of defects in the design elements of the metal structures of the handling equipment which operate under cyclic loading with possible peak dynamic overloads. At cyclic loading of design elements of a metal structure in operating conditions slow development of defects which sizes are much smaller than critical is possible. In this case, the calculation of the limit state is insufficient and the performance of the structure can be fully characterized by its residual life - the operating time after which the initial defect reaches a critical size and the metal element is completely destroyed.

Required initial data for calculation:

- geometric parameters of initial defects, their type, configuration, dimensions, etc.;

- stress distribution in the area of defects, as well as patterns of load change over time (average load frequency $\omega$, load cycle asymmetry, etc.);

- nature and parameters of action of aggressive environment (for example, sea fog, deposition of dust of chemically active substances);

- mechanical characteristics of the material (yield strength $\sigma_{\mathrm{T}}$, Young's modulus E, Poisson's ratio $v$ ) and parameters of their crack resistance (limiting $K_{\mathrm{fc}}, \delta_{\mathrm{fc}}$ and threshold $K_{\mathrm{th}}$ values of the coefficient of stress intensity and opening at the crack tip; constants $A_{\mathrm{B}}, m_{\mathrm{B}}, \lambda_{0}$, describing the characteristic function of fatigue failure).

The calculation of the residual resource includes 2 stages: the first determines the period $\mathrm{N}_{3}$ from the origin of the macrocrack at the apex of the initial concentrator, the second investigates the kinetics of the development of this macrocrack to a critical value.

$$
\Phi(\lambda) \frac{\partial R}{\partial N}\left[R^{-2}\left(\frac{\partial R}{\partial \varphi}\right)^{2}+1\right]^{1 / 2}=1
$$

The solution of this problem is carried out by numerical integration of the differential equation (1) on the unknown function $\mathrm{R}(\mathrm{N}, \varphi)$, which describes the moving contour of the crack, under the initial condition

$$
\left.R\right|_{N=0}=R_{0}(\varphi)+l_{p}(\varphi)
$$

where $R_{0}(\varphi)$ is the contour of the initial concentrator; $1 p$ is the value of the plastic zone at its apex. 
The parameter $\lambda=1-\sqrt{\delta / \delta_{f c}}$.

The solution of equation (1) specifies the position of the crack contour at different points in time. The residual life of the structure corresponds to the value of the number $\mathrm{N}^{*}$ load cycles, at which the opening at the crack tip reaches a critical value $\delta=\delta_{\text {fc }}$. Defects for which the values of $\mathrm{N}^{*}$ do not exceed the estimated service life of the structure will not lead to its premature destruction and are safe.

The results of calculations on the brittle strength and durability of the elements of the metal structures of the handling equipment, performed by the above methods, form the theoretical basis for the development of measures to prevent their sudden destruction in operation.

The use of modern methods of quality control of metal structures, providing a significant increase in resolution when detecting defects, creates conditions in which the introduction of methods for assessing the allowable and critical parameters of cracks is one of the priorities of operational practice.

The method of calculating the residual life of rod and plate elements of metal structures with central and edge symmetrical cracks, the most common in truss metal structures of cranes. It takes into account: the finiteness of the size of the elements in length and width; thickness of elements from 6 to $10 \mathrm{~mm}$; compliance with the conditions of auto modeling (through, long cracks); the destruction of the elements occurs by the mechanism of separation; test conditions, temperatures correspond to operating.

The task of determining the Stress Intensity Factor in a wide range of crack lengths, taking into account all finite dimensions, is quite difficult if it is solved by precise analytical approaches. Recently, approximate numerical and interpolation methods of solution that can be used for engineering practice have been developed.

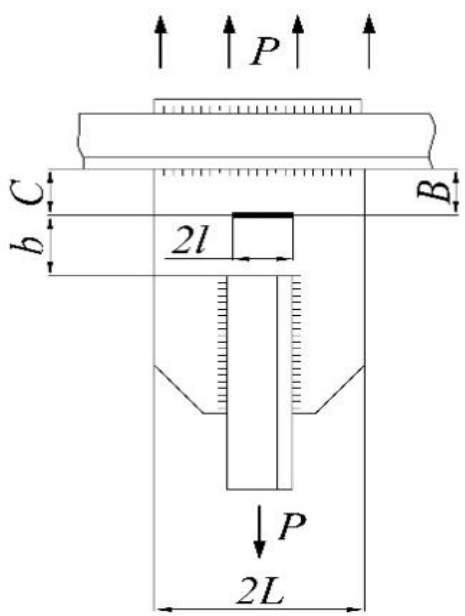

a

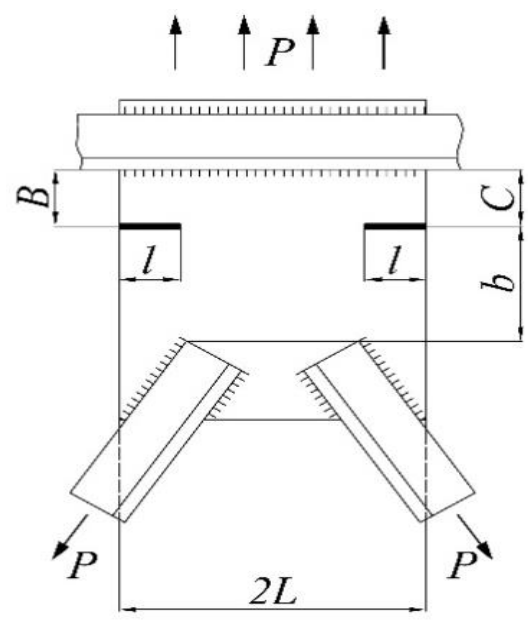

b

Fig. 3. Elements of a metal structure with cracks: $\mathbf{a}$ - central; $b$ - edge, symmetrical 
The structural element (Fig. 3) in the form of a plate weakened by a crack is a two-parameter body with parameters $\mathrm{L}$ and $\mathrm{B}$, so $\mathrm{K}_{\mathrm{I}}$ can be represented as ${ }^{13}$ :

$$
K_{\mathrm{I}}=P \sqrt{\pi l} \Phi\left(\lambda_{1}, \lambda_{2}\right)=P \sqrt{\pi l}\left[\Phi\left(\lambda_{1}, 0\right)+\Phi\left(0, \lambda_{2}\right)-1\right]
$$

where $\mathrm{P}$ is the load parameter; 1 is the length of the crack; $\Phi(\lambda 1,0), \Phi(0, \lambda 2)$ are dimensionless functions defined in the problem of boundary equilibrium of a band of unlimited length and finite width weakened by a crack which is respectively parallel and perpendicular to its edges.

Using the method of boundary interpolation, $\mathrm{K}_{\mathrm{I}}$ can be represented as

$$
K_{\mathrm{I}}=\sigma_{\text {nom }} \alpha
$$

where $\sigma_{\text {nom }}-$ nominal stresses in the net cross section of the isthmus crack; $\alpha$ is the geometric part of $K_{I}$.

The values of $\sigma_{\text {nom }}$ and $\alpha$ for a crack of arbitrary length are determined from the interpolation relations:

$$
\sigma_{\text {nom }}=\left[\sqrt{\sigma_{\text {nom }}^{(0)}}+\sqrt{\sigma_{\text {nom }}^{(1)}}-\sqrt{\left(\sigma_{\text {nom }}^{(1)}\right)_{\lambda=0}}\right]^{2}
$$

where $\sigma_{\text {nom }}^{(0)}, \sigma_{\text {nom }}^{(1)}-$ nominal stresses for short and long cracks, respectively;

$$
\alpha=\alpha_{0} \alpha_{1} /\left(\alpha_{0}^{2}+\alpha_{1}^{2}\right)^{-1 / 2}
$$

where $\alpha_{0}, \alpha_{1}-$ geometric parts of Stress Intensity Factor, for short and long cracks respectively.

When determining the Stress Intensity Factor for a plate with a central crack, the elements of metal structures (Fig. 3, a) are modeled by a typical power scheme in the form of a plate (width $2 \mathrm{~L}$, length $2 \mathrm{~B}$ ), which is weakened in the central section by a crack length 21 (Fig. 4, a) and stretched by the forces of intensity $\mathrm{P}$.

We introduce the notation:

$$
\lambda_{1}=l / L, \quad \lambda_{2}=l / B, \quad \eta=B / L, \quad \lambda_{2}=\lambda_{1} / \eta
$$

Under the boundary condition, when $\lambda 1 \neq 0, \lambda 2 \rightarrow 0$, and the force $\mathrm{P}$ is applied at infinity, according to [10].

13 Dashhenko A. F. Chislenno-analiticheskij metod granichnyh jele-mentov [Numerical-analytical method of boundary elements]. Odessa : VMV, 2010. T. 1. $415 \mathrm{~s}$. T. $2.510 \mathrm{~s}$. 


$$
K_{\mathrm{I}}^{(1)}=P \sqrt{\pi l}\left[\left(1-\lambda_{1}\right)\left(1+1,4674 \lambda_{1}\right)\right]^{-1 / 2}
$$

where

$$
\Phi\left(\lambda_{1}, 0\right)=\left[\left(1-\lambda_{1}\right)\left(1+1,4674 \lambda_{1}\right)\right]^{-1 / 2}
$$

Under the boundary condition, when $\lambda 1 \rightarrow 0, \lambda 2 \neq 0$, the function $\Phi(0, \lambda 2)$ Stress Intensity Factor according to [11] at $0<\lambda_{2} \leq 0,5$ has the form:

$$
\Phi\left(0, \lambda_{2}\right)=1+1,1418 \lambda_{2}^{2}-0,6048 \lambda_{2}^{4}
$$

if $\lambda_{2} \geq 0,5$

$$
\Phi\left(0, \lambda_{2}\right)=\frac{\left(0,0957+0,4533 \lambda_{2}-0,6733 \lambda_{2}^{2}+0,3333 \lambda_{2}^{3}\right)}{\left(0,6733+\lambda_{2}\right)}
$$

Knowing the values of $\Phi\left(\lambda_{1}, 0\right)$ and $\Phi\left(0, \lambda_{2}\right)$ from expressions (9) - (11), according to formula (3) we determine Stress Intensity Factor for arbitrary parameters $\lambda_{i} ; \mathrm{i}=1 ; 2$.

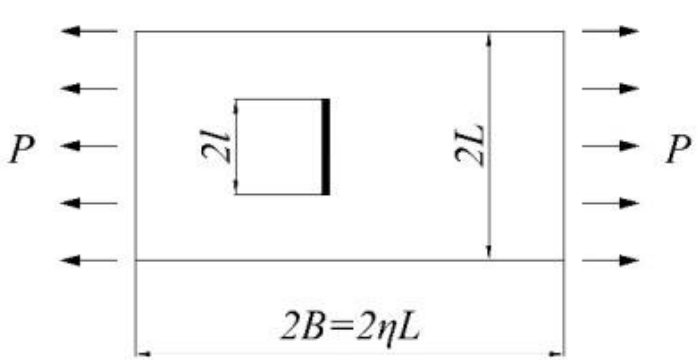

a

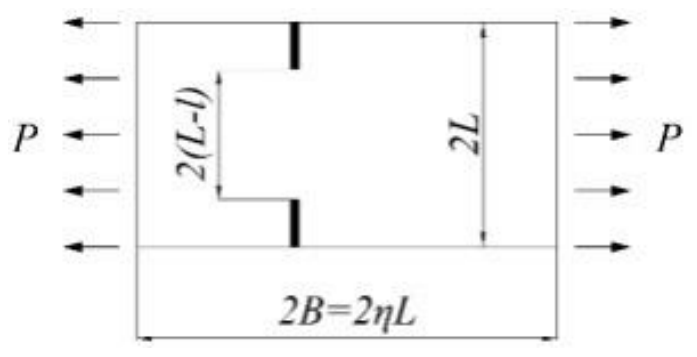

б

Fig. 4. Model loading schemes of structural elements (Fig. 3) in the form of plates with a width of $2 \mathrm{~L}$ and a length of $2 \mathrm{~B}$ : $a$ - with a central crack; $b$ - with edge symmetrical ones

When determining Stress Intensity Factor for a plate with edge cracks, the elements of metal structures (Fig. 3, b) are modeled by a typical power scheme in the form of a plate (width $2 \mathrm{~L}$, length $2 \mathrm{~B}$ ), which is weakened by two edge symmetrically located cracks of length 1 (Fig. 4, b), to which the force $\mathrm{P}$ is applied.

Under boundary conditions, when $\lambda_{1} \neq 0, \lambda_{2} \rightarrow 0$ by a known method $[12,13]$ a solution is obtained for a band with two edge cracks:

$$
K_{\mathrm{I}}^{(1)}=1,12 P \sqrt{\pi l}\left[\left(1-\lambda_{1}\right)\left(1+2,0951 \lambda_{1}\right)\right]^{-1 / 2}
$$

The formula Stress Intensity Factor for a limited length plate is found from the relation: 


$$
\boldsymbol{K}_{\mathrm{I}}=\boldsymbol{K}_{\mathrm{I}}^{(\mathbf{1})} \boldsymbol{K}_{\mathrm{I \Gamma}} / \boldsymbol{K}_{\mathrm{I \Gamma}}^{(\mathbf{1})}
$$

where $K_{\mathrm{I} \Gamma}$ - is the value of Stress Intensity Factor for a limited length plate with a central crack, formula (10) and (11); $\mathrm{K}_{\mathrm{I \Gamma}}^{(1)}$ - the value of Stress Intensity Factor for the band with a crack, formula (8).

The legitimacy of relation (13) is substantiated by the fact that the influence of the plate length is described by a functional dependence which in the case of a central crack in the plate (Fig. 4, a) and two edge cracks in the plate (Fig. 4, b) is considered the same. As a result, Stress Intensity Factor is equal to

$$
K_{\mathrm{I}}=P \sqrt{\pi l} \widetilde{K}
$$

where

$$
\widetilde{K}=1,12\left(1+0,5708 \lambda_{1}\right)^{1 / 2} \Phi\left(\lambda_{1}, \lambda_{2}\right)\left(1+2,0951 \lambda_{1}\right)^{-1 / 2}
$$

According to [10], the fatigue crack kinetics is determined from the differential equation

$$
\Phi(\varepsilon)\left[1+R^{-2} \frac{\partial R}{\partial \alpha}\right]^{1 / 2} \frac{\partial R}{\partial N}=1
$$

under initial conditions

$$
\vec{R}(\mathbf{0}, \alpha)=\vec{R}_{\mathbf{0}}(\alpha)
$$

where $\overrightarrow{\mathrm{R}}$ - is the radius vector of the crack contour, which initially coincides with the radius vector $\overrightarrow{\mathrm{R}}_{0}$ of the initial contour of the crack; $\alpha-$ is the coordinate angle of the polar coordinate system; $\Phi(\varepsilon)$ - is a characteristic function of fatigue failure which under given conditions is a characteristic of the material. Where

$$
\varepsilon=1-K_{\mathrm{I}} / K_{f c}
$$

To find the period $\mathrm{N}$ of the subcritical crack growth in the most general case, it is necessary to integrate equation (16), which is associated with significant mathematical difficulties. In the case of the spread of cracks in the plate elements, it will take the form:

$$
\Phi(\varepsilon) \frac{d l}{d N}=1
$$

and the period of subcritical crack growth during its growth from $1_{0}$ to $1_{\mathrm{K}}$ will be: 


$$
N_{k}=\int_{l_{0}}^{l_{k}} \Phi(\varepsilon) d l
$$

Analysis of the results of numerical experiments shows that the characteristic function $\Phi(\varepsilon)$ will be such that grows monotonically. It is represented graphically by an $S$-shaped curve in the coordinates $\Phi-\varepsilon$. The value of $\varepsilon_{0}$ corresponds to the limit value $\mathrm{K}_{\text {th }}$ of crack opening, below which the crack does not propagate. The full range of the function is described by the relation

$$
\Phi(\varepsilon)=A\left\{\left[\frac{\varepsilon_{0}}{\left(\varepsilon_{0}-\varepsilon\right)}\right]^{m}-\mathbf{1}\right\}
$$

The diagram of fatigue failure in the coordinates $\mathrm{V}-\Delta \mathrm{K}$ (Fig. 5) is well described by formula (21), that is $\mathrm{V}=\Phi^{-1}(\varepsilon)$ Thus for curve $1-\mathrm{A}_{\mathrm{B}}=2 \cdot 10^{4} \mathrm{M}^{-1}$, $\mathrm{m}_{\mathrm{B}}=1,4$; for curve 2 respectively $-\mathrm{A}_{\mathrm{B}}=9 \cdot 10^{4} \mathrm{M}^{-1}, \mathrm{~m}_{\mathrm{B}}=1,15$. Characteristic function of curve 1 :

$$
\Phi(\varepsilon)=2 \cdot 10^{4}\left\{\left[\frac{(26,3-3,63)}{\left(K_{1}-3,63\right)}\right]^{1,4}-1\right\}
$$

where $K_{I}-$ the value of Stress Intensity Factor for the plate, which is weakened by a crack.

Dependence (21) is numerically integrated on EOM in the range from $l_{0}$ to $l_{\mathrm{K}}$ for the plate weakened by the central crack. As the results of calculations show (Fig. 6), taking into account the finiteness of the dimensions of structural elements affects the resource and the allowable dimensions of defects. Thus, the change in the point of application of the load, if other conditions are equal, causes a decrease in the critical crack size (at $\eta=1$ relative to $\eta \rightarrow \infty$ up to $10 \%$ ), and resource $\mathrm{N}$ differs in the direction of reduction by almost an order of magnitude.

One of the advantages of this method is the ability to estimate the residual life, allowable and critical parameters of cracks by simple calculations (in operating conditions, at industrial facilities). For example, if a central through crack is detected in a metal structure (Fig. 3, a), the following operations must be performed: measure the width $2 \mathrm{~L}$ of the plate and the length of the crack 21 ; to determine $\eta$ find the size B on the minimum distance of the crack to the place of attachment of the element, i.e. the point of application of the load (from the sizes $\mathrm{b}$ and $\mathrm{c}$ choose the smaller); determine the level of load in relation to $\sigma \mathrm{t}$ by calculation, strain gauge, taking into account the coefficient of utilization of the machine by load capacity, etc. (in the absence of the possibility of such measurements take the limit value $\sigma=0,8 \sigma_{\mathrm{T}}$ taking into account the possible stress concentration). Numerous studies using strain gauge methods have established that the operational and design loads in the metal structures of cargo handling equipment are in the range from 0.2 to $0,3 \sigma_{\mathrm{T}}$. 


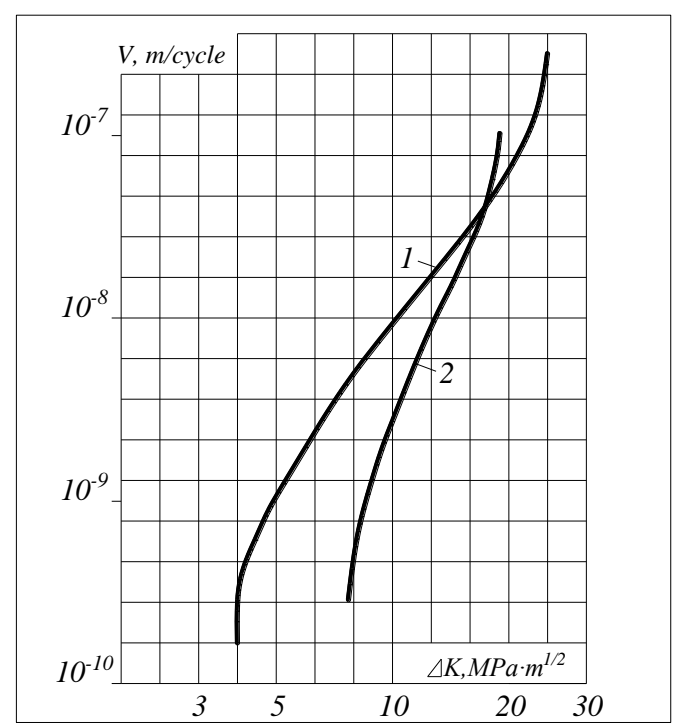

Fig. 5. Diagrams of fatigue failure of steel 20 at different temperatures:

$$
1-\mathbf{t}=20^{\circ} \mathbf{C} ; 2-\mathbf{t}=-\mathbf{7 0}^{\circ} \mathrm{C}
$$

Characteristics of crack resistance: $1-\Delta K_{\mathrm{fc}}=26,3 \mathrm{MPa}, \Delta K_{\mathrm{th}}=3,63 \mathrm{MPa} ; 2-\Delta K_{\mathrm{fc}}=20,0$ $\mathrm{MPa}, \Delta K_{\mathrm{th}}=7,41 \mathrm{MPa}$.

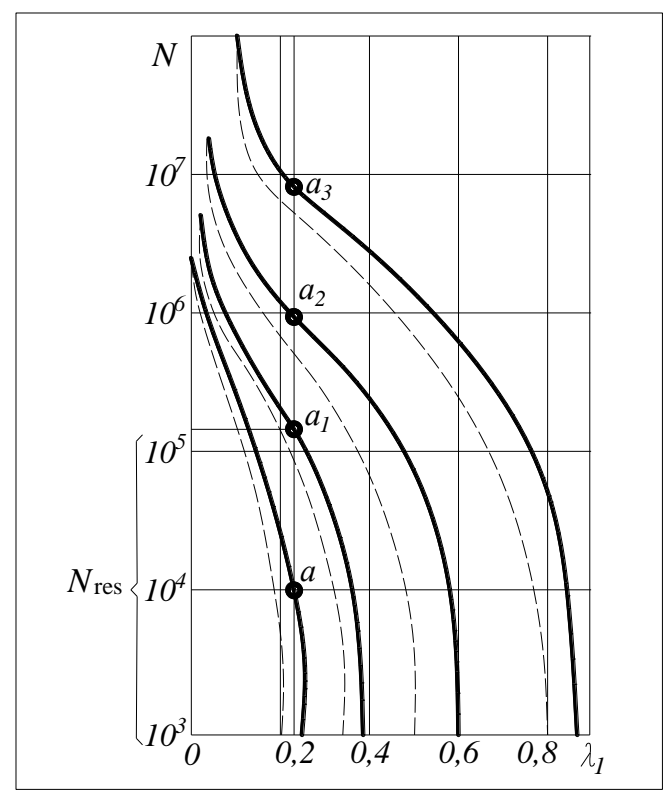

Fig. 6. Diagrams of survivability of plate elements of metal structures made of steel 20 with a central crack at stress levels $\sigma_{\mathrm{T}}$, that make up 70, 140, 210, $280 \mathrm{MPa}$ (respectively curves 1-4): solid lines $-\eta=\infty$; dashed lines $-\eta=1$.

Residual life and maximum allowable parameters of cracks are determined by survivability diagrams (Fig. 6). For example, if $2 L=300 \mathrm{Mм}, 2 B=500 \mathrm{Mм}$, $2 l=66 \mathrm{MM}, \sigma=0,6 \sigma_{\mathrm{T}}$, then, calculating $\lambda_{1}=0,22, \eta=1,7$, we determine the point $a$ on curve 4 (solid line, since $\eta>1$ ). In this case, the residual resource $N_{\text {res }}=9,9 \cdot 10^{3}$ cycles, and the critical crack size after operating $N_{\text {res }}$ at $\lambda_{1}=0,38$ will be $2 l_{\mathrm{cr}}=114 \mathrm{MM}$. 
In the same sequence determine $N_{\text {res }}$ and $l_{\text {cr }}$ or other load levels (points $a_{1}$, $a_{2}, a_{3}$ ). For $\sigma=0,8 \sigma_{\mathrm{T}}$ (curve 3, point $a_{1}$ ) the given 1 approaches the dangerous region of critical values $N_{\text {res }}=1,99 \cdot 10^{5}$ cycles, $2 l=72 \mathrm{MM}$ at $\left.\lambda_{1}=0,24\right)$, and in the case of $\eta \leq 1$ the specified crack length is already more than $l_{\mathrm{cr}}$. By reducing the load parameters to the levels of $0,4 \sigma_{\mathrm{T}}$ and $0,2 \sigma_{\mathrm{T}}$ (respectively points $a_{2}$ i $a_{3}$ ), it is possible to significantly increase the residual life (in this case up to $10^{6} \ldots 10^{7}$ cycles with increasing allowable values of $l_{\text {cr }}$ ).

This provides conditions for controlling the process of development of fatigue cracks in metal structures by changing the load parameters of the handling equipment.

\section{CONCLUSION}

The proposed methods for estimating the residual life of port handling equipment make it possible to solve the following practically important problems:

1. To determine the most probable areas of fragile destruction of structures, to develop ways to strengthen the relevant elements and components at the stage of their design;

2. To rank the materials used for the manufacture of design metal structures of handling equipment according to their ability to resist destruction under different load conditions and to issue recommendations for their optimal choice;

3. To regulate the frequency and methods of defectoscopic control of the most responsible elements of equipment that ensure timely detection of dangerous damage in operating conditions;

4. To determine the design loads, which at a given technology of manufacturing structures (i.e. at a given level of defects of their elements) can lead to premature failure;

5. To establish the sizes of admissible defects at which the estimated service life of metal structures of the equipment is provided, and to substantiate requirements to quality of manufacturing of highly loaded elements which are not subject to control in operational conditions;

6. To carry out an examination of cases of destruction of individual elements and components of metal structures of equipment that occurs during operation and establish their causes.

7. The practical implementation of these recommendations makes it possible to significantly increase the strength and durability of handling equipment and increase the reliability of its operation.

\section{SUMMARY}

The paper presents the main theoretical approaches to the calculation of the residual life of cargo handling equipment. The necessary conditions and the 
basic concept of estimation of the residual resource of the equipment are stated. The life cycle of the equipment is described and the resource parameters at each stage are determined.

The comparison of the existing approaches of resource recovery of handling equipment in the system of planned and preventive repairs and repairs according to the actual technical condition is carried out. The main factors of influence of the surrounding operating conditions of the equipment on the rate of depletion of its resource are established. The introduction of new parameters in the calculation model which characterize the processes of destruction of metal structures of equipment is proposed. The method of calculating the residual life of the metal structure of the equipment including the period of origin of the crack and its development to a critical value is introduced. The calculated model schemes of elements of a metal structure with cracks with defined characteristic functions of fatigue failure are stated. Diagrams of survivability of materials of metal structures which use provides management of process of development of fatigue cracks are constructed.

\section{REFERENCES}

1. Timashev S. A. Reliability of large mechanical systems. M.: Nauka, 1982. $184 \mathrm{p}$.

2. Bolotin V. V. Resource of machines and constructions. M.: Mashinostroenie, 1990. 448 p.

3. GOST 27.302-86. Reliability in technology. Methods for determining the permissible deviation of the technical condition and forecasting the residual life of the components of machine units.

4. GOST R 27.002-2009. Reliability in technology. Basic concepts, terms and definitions.

5. RD 26.260.004-91 Forecasting the residual life of the equipment to change the parameters of its technical condition during operation Publishing house NIIHIMMASH, M. 1992. 50 p.

6. Pustovyy V. M., Trykolenko M. V., Semenov P. O. and others. Regulations on planned and preventive repairs of port cranes of seaports // Ministry of Transport of Ukraine, State Labor Inspectorate of Ukraine. Kyiv, 2005, part $1-250$ p., part $2-426$ p.

7. Zubko N. F., Yatsenko V. A. Operation and repair of port handling machines: [Textbook. for spec. Mechanization of port cargo handling works of universities], 423, [1] p. il. $22 \mathrm{~cm}$, M. Transport 1987.

8. Non-destructive testing: Handbook: In 7 vols. ed. V. V. Klyueva. V. 7 : In 2 books. Book 1: V. I. Ivanov, I. E. Vlasov. Acoustic emission method / Book 2: F. Ya. Balytskiy, A. V. Barkob, N. A. Barkova and others. Vibrodiagnostics. M.: Mashinostroenie, 2005. 829 p.: il. 
9. Pustovoy V. N. Metal structures of hoisting machines. Destruction and forecasting of residual resource. M.: Transport, 1992. $256 \mathrm{p}$.

10. Weinson A. A. Lifting and transport machines: A textbook for universities in the specialty Lifting and transport, construction, road machinery and equipment. 4th ed., reworked. and ext. M.: Mashinostroenie, 1989. 536 p.: il.

11. Pustovoy V. N. Metal structures of hoisting machines. Destruction and forecasting of residual resource. M.: Transport, 1992. $256 \mathrm{p}$.

12. Andreykiv A. E. Spatial problems of crack theory. Kiev: Science. opinion, $1982.348 \mathrm{p}$.

13. Panasyuk V. V., Savruk M. P., Datsyshin A. P. Stress distribution near cracks in plates and shells. Kiev: Naukova Dumka, 1976. 444 p.

\section{Information about the authors: Pustovyy V. M.,}

Doctor of Technical Sciences, Professor, Head of the Lifting and Transport Machines and Engineering of Port Technological Equipment Department,

Odessa National Maritime University 34, Mechnikov str., Odessa, 65029, Ukraine ORCID ID: orcid.org/0000-0002-2458-2717

Semenov P. O., Candidate of Technical Sciences, Senior Lecturer of the Lifting and Transport Machines and Engineering of Port Technological Equipment Department,

Odessa National Maritime University 34, Mechnikov str., Odessa, 65029, Ukraine ORCID ID: orcid.org/0000-0003-4121-6011

Nesterov O. A., Postgraduate of the Lifting and Transport Machines and Engineering of Port Technological Equipment Department,

Odessa National Maritime University 34, Mechnikov str., Odessa, 65029, Ukraine ORCID ID: orcid.org/0000-0002-8717-5289 